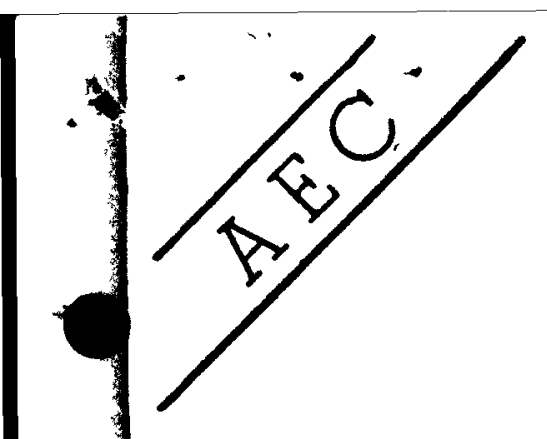

$$
\begin{aligned}
& \text { CLTIIN FTFIRENCE NUMBER } \\
& \text { AED-CONA- } 63-163-7 \\
& \text { ATOMIC ENERGY COMMISSION } \\
& \text { WashingtON, D.C. } 20545
\end{aligned}
$$

American Nuclear Society National Topical Meeting Aerospace Nuclear Safety Albuquerque, New Mexico October 1-4, 1963

Tel. HAzelwood 7-7831

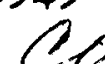

2<smiles>[Li]C1C=C1</smiles>

octoper 1,1963$)$
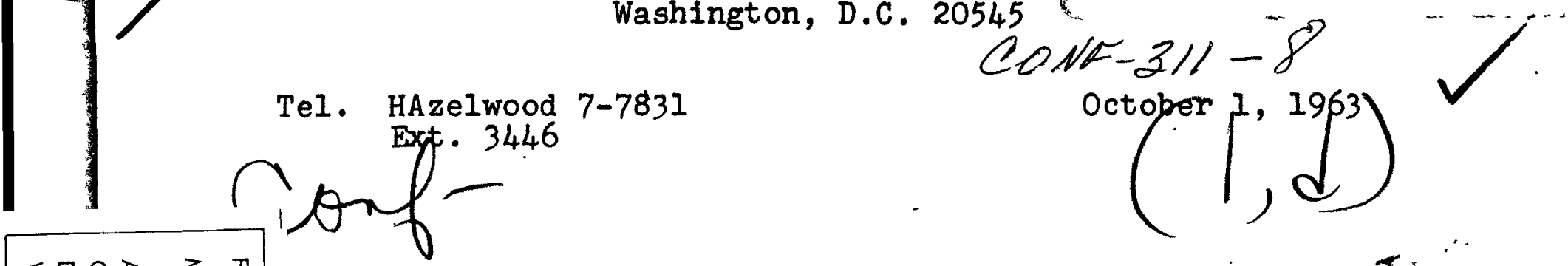

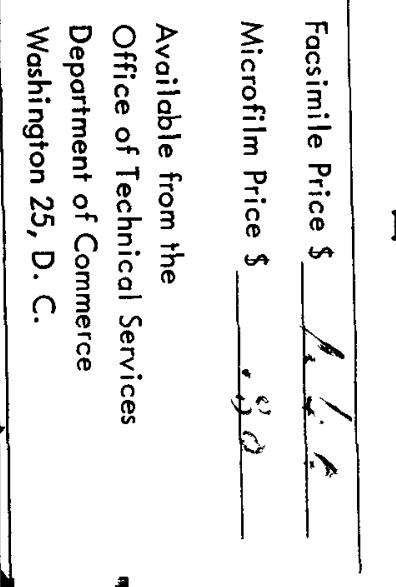

Remarks by Dr. Frank K. Pittman, Director Division of Reactor Development

U. S. Atomic Energy Commission at the

National Topical Meeting of the American Nuclear Society on Aerospace Nuclear Safety

Cole Hotel, Albuquerque, New Mexico October 1, 1963

\title{
AEC AEROSPACE SAFETY PROGRAMS AND PHILOSOPHY
}

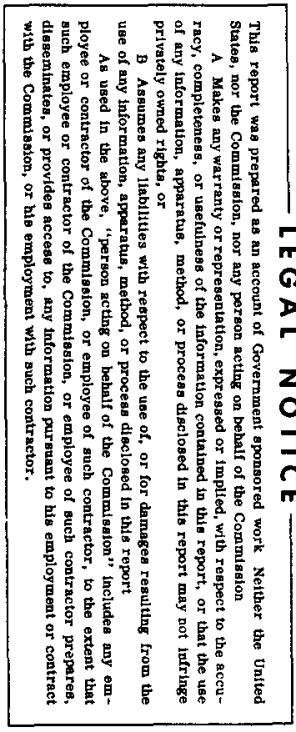

INTRODUCTION

Just recently, SNAP-9A, powered by radioisotopes, was launched from Vandenberg Air Force Base as a power source for an operational satelliie. This launch, among other things, culminated two iong years of aerospace nuclear safety research, development, rest, analysis, and evaluation. It also demonstrated how a large number of organizations and many scientific and technical issiplines can collectively and effectively get a job done. Although we had no doubts that SNAP-9A could be used in this aerospace mission with a high degree of safety, we recognize that we have barely cross. d the threshold of the broad subject of aerospace nuclear afety. The space systems are so varied and our experience with nuclear units in space so limited that it seems quite clear that only the surface of aerospace nuclear safety technology has been scratched. A lot of work in aerospace safety analysis, research, development, and testing is ahead of us before we can assure the safe use of nuclear devices in a large number of applications.

HISTORY

Although the course of aerospace nuclear safety has been obviously short. there is nevertheless some history that might be well to rela: $\epsilon$ briefly. Back in 1959, the SNAF Hazards Committee and ANF tife Sciences Working Group within the AEC recognized the neea for some kind of aerospace nuclear safety criteria 


\section{DISCLAIMER}

This report was prepared as an account of work sponsored by an agency of the United States Government. Neither the United States Government nor any agency Thereof, nor any of their employees, makes any warranty, express or implied, or assumes any legal liability or responsibility for the accuracy, completeness, or usefulness of any information, apparatus, product, or process disclosed, or represents that its use would not infringe privately owned rights. Reference herein to any specific commercial product, process, or service by trade name, trademark, manufacturer, or otherwise does not necessarily constitute or imply its endorsement, recommendation, or favoring by the United States Government or any agency thereof. The views and opinions of authors expressed herein do not necessarily state or reflect those of the United States Government or any agency thereof. 


\section{DISCLAIMER}

Portions of this document may be illegible in electronic image products. Images are produced from the best available original document. 
on which to base safety analyses and judgments for the use of aerospace nuclear devices. Based on their recommendations and those of the DOD, NASA, and President's Science Advisor that such criteria be established by the AEC, the Aerospace Nuclear Safety Board was formed within the AEC.

This Board was set up to analyze and predict the possible effect of nuclear space devices upon the health and safety of the public, to recommend standards of safe practice for the employment of nuclear powered space devices, and to recommend policy and procedures to be followed in regulating the use of nuclear energy for devices in space vehicles and satellites.

It was readily apparent to the Board that nuclear safety questions would arise as a result of missile launch pad failures, pre-orbital failure of the space vehicles, release to the atmosphere or into space of radioactivity and random return to earth of intact or partially intact devices as a result of failure to burn up on re-entry or deviations from programmed missile trajectories. In the interests of assuring safety, the Board felt that it would be realistic to expect compromises with respect to performance, economy and operational flexibility in the early flights, but it felt that such compromises would be reduced as a result of the accumulation of experience and the advancement of the space technology.

About the same time, two other groups, the SNAP Safety Committee and the Joint Committee on Hazards of Nuclear Space Systems, took a hard look at the programs. The SNAP Safety Committee reached the conclusion that the most desirable means for disposal of the radioactive material would be either to assure that the heat source would remain in orbit throughout the effective lifetime of the isotopic fuel or fission products (after a reactor is shut down); or to inject the device into a solar orbit from its initial terrestrial orbit; or to return it from a terrestrial orbit to a specific location on the earth's surface.

However, because the state of the missile art at that time was not sufficiently advanced to assure that these procedures would work with adequate dependability, this group believed that the planned return of the intact isotope containing package (or reactor with a fission product inventory) was inadvisable except under specific circumstances.

All of the early groups, as well as those of a more recent vintage, agree that for the proposed space missions, and assuming adequate reliability and performance of the nuclear device itself, the achievement of the normal operational orbit 
would not result in a hazard to people; and that the only hazards would be the result of an aborted mission or missile malfunction. This leads to the conclusion that basic to the design and use of a safe nuclear device safely in space, is knowledge and understanding of two things: 1) the missile abort or malfunction environment to which the nuclear device may be subjected, and 2) the effect of these environments on the nuclear device.

Back in 1960, there was a reasonable understanding of what the radiobiological hazards of the various radioisotopes would be if people were exposed to them on the surface of the earth. Dependent on the form, ground concentrations, and location of the isotopes, the potential hazards could be related to a generally accepted framework of radiation protection. This gave us a fair handle on the end point of the safety problem, but the most important pieces of the total problem were essentially unknown -- the abort environments and the effect of such environments on the nuclear device.

Thus, our early endeavors to formulate aerospace nuclear safety philosophy were directed for the most part toward the nuclear considerations, with our attention focused on radiobiological factors which constituted the end point of the safety problem. In the next few years, however, from 1960 - 1962, we became so engrossed in defining the unknowns of our problem -- the missile abort environments and their effects - - that we, to some extent, neglected the area in which we had made a good beginning -- the analysis of the potential radiation exposure. We are now achieving a much more balanced approach to our problem.

It has now become apparent that the best approach to the analysis and evaluation of aerospace nuclear systems safety is through coordinated effort across the board to first define and analyze the missile abort environments, second to identify the probability that such environments can result in the release of radioactivity from the nuclear device in the biosphere, and third to analyze the extent of the hazards. associated with this release. The coordination of the physicists, aerodynamicists, aeronautical engineers, metallurgists, electronic engineers, meteorologists, oceanographers, biomedics, etc., has shown us that we can reduce or eliminate effort on some problems because there is little or no safety problem involved, and has allowed us to make a preliminary scoping of the areas where true safety problems seem to exist. By initiating such a coordinated safety analysis effort at an early stage, we have made possible a continuous evaluation of the safety aspects of the several aerospace nuclear programs 
during their development period. This has been particularly useful in pointing out where the safety efforts should be concentrated.

We are now beginning to learn that an understanding of all aspects of a program is necessary and that it takes the coordinated effort of experts in all the aerospace and nuclear safety disciplines for adequate safety assurance. The analysis of SNAP-9A has given us some insight of how much input can be expected for any one specific discipline and how the efforts of all groups must be overlapped and coordinated to eliminate the voids.

It is axiomatic that as we move ahead in the aerospace nuclear era, further progress and improvement in our safety analysis capability must be made.

\section{TECHNICAL PHILOSOPHY}

The issue of safety is paramount. But, when we say this, we should and must recognize the concept of acceptable risk commensurate with the advantages and benefits to be achieved. The trivial solution of "zero use equals zero risk" we can dispense with right now.

The aerospace use of nuclear systems presents an exciting and interesting challenge because of the variety and complexity of the vehicle systems and missions that these systems are to accomplish. It is fairly certain even now that the safety problems are not represented by a single question with a single solution. There are likely to be a variety of acceptably safe solutions to a multitude of problems. The aerospace nuclear safety programs must be flexible enough to solve each of the safety problems in such a way that the safety approach to a specific system is compatible with the physical constraints of the system.

An extensive safety analysis and evaluation and test program on the SNAP-9A device that assisted us in obtaining approval to fly has been accomplished. Many lessons were learned in the safety iterations for this program and many more likely will become apparent. One of the things that we have known for a long time was that the safety of a system could be "paper-studied" at length without developing an irrefutable, data supported safety evaluation. Our SNAP-9A evaluation served to reaffirm and strengthen this truism. At some point in the safety iterations, you have to supplement the "paper-studies" with experimental data. For maximum safety assurance of systems requiring program approval at the highest levels of government, experimental evidence on which to base the safety of a system is imperative. 
SNAP-9A has emphasized to us that safety involves the nuclear device and its associated components -- the whole system and its mission. However, it has also taught us that the significant, controlling problems on the safety or degree of safety of the proposed use in aerospace involve an understanding of the missile malfunctions or aborts, the probabilities of such occurrences, the environments associated with the aborts or malfunctions, and their effects on the nuclear device. The environments are not only severe, but extremely complex to analyze and understand.

Although the conclusions on the safety of SNAP-9A were based in part on the judgment of the best technical competence in the nation; the desirability of further supporting experimental and test data was also evident. The need for developing fundamental data on each of the missile abort environments cannot be over-emphasized. These data must be obtained at an early date because of the control the environments have on the design of the device and the safety philosophy to be adapted to the mission.

I have mentioned flexibility of design and safety systems. Up to now the major safety philosophy used in the design of aerospace nuclear systems has been complete containment of the radioactivity during all phases of early launch aborts and complete burn-up on re-entry at or near orbital velocities. However, we have only put three small devices in orbit under this general philosophy. There are many, many more to come -- of all sizes, shapes and types.

With the appearance of larger, more complex, nuclear systems in the relatively near future, it may well be that the current philosophy of design may not be the best. We are looking for other ways of assuring safety as well as providing maximum flexibility for aerospace use. Envisioned are such schemes as:

1. Controlled re-entry.

2. Selection of a fuel form that would permit high altitude burn-up or intact re-entry without the release of the radioactivity to the biosphere.

3. In-orbit recovery by another satellite for return to earth or ejection into a solar orbit.

4. Positive destruct devices on re-entry to assure disassembly and burn-up on re-entry at extremely high altitudes. 
As previously stated, we are not approaching the aerospace nuclear safety program on a single problem -- single solution basis. Each program or system could for quite a time present a different problem that requires a different approach.

Real hazards to the public are not the only underlying motives to a flexible safety approach to the use of aerospace nuclear devices. We must also consider the impact of public opinion, both here and abroad. Even though we could show that the use of nuclear devices in aerospace will not result in significant levels of radioactivity to which people may be exposed, and even though these conclusions may be reached on very conservative bases, we would be something less than realistic if we did not recognize and anticipate the potential problems associated with public and political reaction in this area. Public acceptance from both a political and psychological viewpoint will ease the way to the widespread safe use of nuclear power in space. It is important that this aspect of the business be given adequate consideration and attention since -- to be pragmatic - it is conceivable that the factors involved may in some cases be governing ones.

\section{SAFETY PROGRAM}

In order to support our flexible aerospace nuclear safety philosophy and to assure the safe use of these devices in space, an extensive aerospace nuclear safety test program is necessary. The recommendations of the Aerospace Nuclear Safety Board and the recognition that an across-the-board aerospace nuclear safety program was required resulted about two years ago in several organizational changes within my staff. A Nuclear Safety group was established under the direction of $\mathrm{Dr}$. Joseph Lieberman with the across-the-board responsibility for nuclear safety $R \& D$, analysis, evaluation and testing.

Within this office, the Engineering and Test Branch conducts prototype-scale tests on the safety of the R\&D reactor systems, and a specific group has been formed to handle the aerospace nuclear safety test programs.

The Sandia Corporation here in Albuquerque was chosen as the primary AEC contractor for the acrospace nuclear safety test program. Because of background experience and available facilities, tests involving reactor excursions were assigned to the Phillips Petroleum Company at the $\mathrm{Na}-$ tional Reactor Testing Station in Idaho. 
Many technical advantages can be accrued from focusing the responsibility for aerospace nuclear safety testing in a single AEC organizational unit, and in a single contractor, particularly one with the field test experience of Sandia. In addition, because such groups are not involved in the development of specific nuclear systems, they can present to the public a degree of objectivity and independence not readily accepted as being present in those responsible for development of the systems. May I hasten to point out that in the final analysis actual safety, -as opposed to analysis thereof, depends upon the developers and designers of the system, and not on those who test and evaluate systems. This requires and, I am glad to say, has resulted in the establishment of an excellent working relationship between the safety test groups and the project development contractors.

ENGINEERING AND TEST PROGRAM

The aerospace safety test program being conducted by the Division of Reactor Development may be divided into five principal areas:

1. Basic or general research and development in areas significant to aerospace safety,

2. Flight testing of generalized prototype and research systems in a true space environment,

3. Ground testing of prototype systems in missile launch abort environments and flight testing in space,

4. Reactor excursion tests, and

5. Independent assessment of the system's nuclear safety.

The objective of this program is to acquire basic data; from this we can extend our knowledge of areas significant to Aerospace Nuclear Safety. Examples of areas to be investigated are:

1. Orbital re-entry burn-up of aerospace nuclear fuels,

2. High altitude dispersion of particles,

3. Oxidation and dispersal of hazardous materials under conditions simulating launch abort fires, and

4. Test verification of analytical aerodynamic equations, (more) 
terials.

5. Space investigation of physical properties of ma-

A series of scientific passenger pod flights has been completed where various test items, containing flare material, were attached to Atlas missiles and released at predetermined altitudes and trajectories. These tests were designed to verify analytical equations developed to predict the re-entry phenomena.

A comprehensive investigation of the physical properties of nuclear aerospace fuels and materials -- particularly at elevated temperatures in the space environment, has been initiated. Knowledge of these properties is essential for an understanding of the behavior of these materials in space and for the development of effective aerodynamic codes for the analysis of space phenomena.

Flight testing will continue to play an important role in our testing program. No ground facilities are available today in which all the parameters of re-entry can be simulated simultaneously, therefore, we will have to continue to use space itself as a laboratory. These tests will be conducted with vehicles purchased by the AEC for that purpose. During Fiscal Year 1963, our first re-entry flight test on the SNAP-1OA reactor system was conducted. The results of this pioneer effort will be described in another session.

During 1964 , we anticipate further re-entry flight tests to get re-entry data on second generation isotope generators as well as reactors. These data will enhance the level of confidence in our ability to predict the sequence of aerodynamic events during re-entry. In addition, "piggy-back" experiments are contemplated, where feasible and in cooperation with DOD and NASA, on Atlas, Titan and space vehicles such as Apollo to acquire data on specific aspects of the aerodynamic heating of reactor and radioisotopic SNAP components on re-entry. Low-level high velocity flights may also be used to ablate fuel material so that the resulting particulate cloud can be sampled by high altitude aircraft.

In the ground test area we have already completed a series of terrestrial environmental tests on the SNAP-IOA core vessel at Holloman Air Force Base, in conjunction with the Air Force. In these tests the reactor core vessel was subjected to various missile launch abort environments to test its reaction to chemical, fire, explosion and mechanical hazards. 
A second phase of these tests on the SNAP-10A reactor is scheduled this coming year.

In isotopic SNAP systems a comprehensive series of ground tests has already been conducted on the SNAP-9A capsule. The terminal velocity and freefall stability of these capsules were obtained in drop tests conducted at the Sandia Tonopah test range.

Flight qualified capsules have been impacted on granite (the most stringent target material) at velocities and temperatures approximating terminal conditions resulting from booster vehicle abort. In addition, the Sandia Radiant Heat Facility has been used to test these capsules under simulated launch fire conditions.

As previously stated, excursion testing of nuclear aerospace reactors under the engineering and test program will be done by the Phillips Petroleum Company at. NRTS. One of the most serious accidents postulated for space reactor systems, both SNAP and nuclear propulsion devices, is a nuclear excursion induced by an accidental immersion of the reactor in water or by an inadvertent rotation of the controls to a critical position. Either of these conditions could conceivably occur under launch abort conditions. Accordingly, safety testing of space reactors will include a series of transient tests, including excursions to the destructive range, to determine the maximum energy release to be expected should such an accident occur. These tests will also determine the ultimate shutdown mechanism of these reactors and will provide information on the quantity and distribution of fission products and radioactive materials as well as the energy release. The initial excursion test designated as SNAPTRAN-3 will model a major accident resulting from launch pad or flight accidents which immerse the nuclear reactor in water. Subsequent tests will investigate the transient behavior of the reactor by varying amounts of reactivity insertion that might result from events which cause rotation of the control elements to a position beyond critical or which results in the inadvertent addition of other reflector materials. Supplementary experiments will explore the transport rates of hydrogen from zirconium hydride fuel elements at high temperatures since this represents the expected inherent shutdown mechanism for SNAP reactor systems using hydride type fuel.

Another area which will be investigated is the disposal of radioisotopes and fission products from nuclear aerospace devices at the end of a useful space mission or after a missile abort. 


\section{ADMINISTRATIVE PHILOSOPHY}

In this relatively new field of nuclear engineering for space application, the AEC has found itself deeply enmeshed with the many branches of the DOD and NASA, not only in the development of the space satellite systems, but the integration of the system to a space vehicle and booster, the launch operations, range operations and safety, and space tracking and utilization. Each group has distinct responsibilities that include safety, and that of necessity, overlap the responsibilities of other groups and agencies. Although the AEC has an over-all and overriding responsibility fot the nuclear safety of the aerospace nuclear systems, this responsibility, in effect, has to be shared with the other agencies where their expertise is relied on to assure safle use of the system. Examples of this sharing are during the launch operations where the AEC depends on the Air Force to assure safety under all launch conditions, and during the pre-orbital boost flight where the Navy or Air Force Range Operations are expected to assure flight within a safe trajectory envelope.

All of the agencies in discharging their safety responsibilities must seek the advice of the experts in the other agencies because the assurance of safe use of an aerospace nuclear system requires the coordination of the technical competence of all the agencies involved. To permit efficient use of this expertise, avoid duplication of effort, and assure a technically-sound depiction of the system safety calls for coordination early in the system development.

Within each of the aerospace nuclear programs, interagency agreements have been written and working groups established to solve interface problems in the system development and to start the analysis of the system safety.

SNAP-9A showed us that these were not enough to present a technically-sound basis for the assurance of safe use in space. When we looked at the safety pieces put together some 6 or 8 months ago by the various working groups in the several agencies, we found that gaps existed in the over-all safety information and that some portions of the jig saw puzzle did not fit together.

A meeting with the nuclear safety groups within the Navy, Air Force, AEC and NASA, was called to decide what had to be done and who would do it. We jointly embarked on an extensive safety analysis and evaluation and test effort to present a complete and technically-competent safety 
analysis upon which could be based approval of the proposed aerospace use of SNAP-9A at the highest levels of government. I would like to stress that this effort was done on an informal basis, but was initiated and carried to a successful completion because of a mutual understanding of each other's safety responsibilities and technical competence by all groups involved.

Not every safety problem was competely resolved. However, the picture was reasonably clear as to the extent of the small risk involved and why even a small risk remained. In certain areas, analysis and personal judgment were not enough to assure beyond a shadow of a doubt that no hazards would result. Even with the advice of the technically expert group assembled, further experimentation would be necessary to competely anwser some of the questions raised. This, of course, is to be expected in any complex aerospace program. SNAP-9A can be used in space with a high degree of nuclear safety. However, in some minds a small risk will exist until the judgment of the experts can be substantiated by experimental data.

If a formal mechanism had existed to draw the agencies together at the outset of the SNAP-9A development and space system integration, it is quite possible that many of the partially resolved problems could have been looked at in a joint agency experimental program. Hopefully, the aerospace agencies can establish a joint agency panel or group that can formally bring the expertise of all the agencies to bear on a program at a very early phase of development. Problem areas would be recognized early, a meaningful safety test program could be conducted on a non-crash basis and, if necessary, there would still be time to modify the system design to assure a high degree of safety. Final approval of a program would be less complex, administratively. Although the individual responsibilities of the agencies can never be delegated or abrogated, the duplication and voids inherent in a system of overlapping responsibilities could be minimized. The discharge of responsibility would be more efficient.

\section{CLOSING REMARKS}

In closing, I would like to reiterate four points:

1. The fundamental parameters of the missile abort environments must be experimentally established to form a technically-sound basis for aerospace nuclear safety philosophies and device design. 
2. Aerospace nuclear systems require a flexible safety approach -- it is not a case of a single problem with $a$ ? single solution.

3. As the aerospace systems become more complex and more agencies are involved in their integration, we will have to work on an interagency basis from the very beginning of each program. Formal means of accomplishing the interchange of this expertise would enhance the over-all safety of the systems.

4. Every effort will continue to be made to minimize the safety barrier to the use of aerospace nuclear systems. It is my firm conviction that safety need not represent an insurmountable obstacle to the widespread and important applications of nuclear devices in aerospace systems. 